\author{
Abdullah Karimi \\ e-mail: akarimi@umail.iu.edu \\ Manikanda Rajagopal \\ e-mail: mrajagop@iupui.edu \\ Razi Nalim ${ }^{1}$ \\ e-mail: mnalim@iupui.edu \\ Purdue School of Engineering \& Technology, \\ Indiana University-Purdue University, \\ Indianapolis, IN 46202
}

\section{Traversing Hot-Jet Ignition in a Constant-Volume Combustor}

\begin{abstract}
Hot-jet ignition of a combustible mixture has application in internal combustion engines, detonation initiation, and wave rotor combustion. Numerical predictions are made for ignition of combustible mixtures using a traversing jet of chemically active gas at one end of a long constant-volume combustor $(C V C)$ with an aspect ratio similar to a wave rotor channel. The CVC initially contains a stoichiometric mixture of ethylene or methane at atmospheric conditions. The traversing jet issues from a rotating prechamber that generates gaseous combustion products, assumed at chemical equilibrium for estimating major species. Turbulent combustion uses a hybrid eddy-breakup model with detailed finite-rate kinetics and a two-equation $k-\omega$ model. The confined jet is observed to behave initially as a wall jet and later as a wall-impinging jet. The jet evolution, vortex structure, and mixing behavior are significantly different for traversing jets, stationary centered jets, and nearwall jets. Pressure waves in the CVC chamber affect ignition through flame vorticity generation and compression. The jet and ignition behavior are compared with high-speed video images from a prior experiment. Production of unstable intermediate species like $\mathrm{C}_{2} \mathrm{H}_{4}$ and $\mathrm{CH}_{3}$ appears to depend significantly on the initial jet location while relatively stable species like OH are less sensitive. [DOI: 10.1115/1.4025659]
\end{abstract}

\section{Introduction}

Hot-jet ignition of premixed combustible mixtures finds application in internal combustion engines [1,2], pulsed detonation engines [3], and wave rotor combustors [4-6]. Chemically active radicals and fast turbulent mixing in the jets create an explosion that is more energetic than a spark [3], allowing rapid ignition of lean mixtures. Further, the penetrating and distributed nature of ignition can overcome mixture nonuniformity and accelerate combustion. By enabling lean stratified mixtures, heat losses to the walls and pollutant emissions can be mitigated. Such ignition is of particular interest for wave rotor combustors, for which a prior model constant-volume combustor (CVC) experiment [5,7] serves for validation of this study. In this CVC, the premixed mixture is ignited by the hot jet produced by combustion of a fuel mixture in a prechamber.

Hot-jet ignition involves flow phenomena such as vortex evolution, jet mixing, and turbulence generation. The presence of reactive species in the jet influences ignition kinetics. A high-speed compressible transient jet in a confined volume is usually accompanied by shock formation due to both jet initiation and combustion pressure rise, leading to subsequent reshaping of flame fronts by shock waves and expansion waves. The ignition delay time for a jet-ignited CVC may be defined as the time from jet initiation to the occurrence of rapid, visible, and pressure-generating heat release [5]. This includes time for physical and chemical processes, unlike purely chemical ignition delay time reported in shock tube and rapid compression studies [8].

A combustible mixture can be ignited by an inert gas jet or reactive gas from another combustion source. Much of the classical literature on jet ignition was concerned with avoiding ignition in mines, and typical experiments used inert hot jets, at low velocities and without inflow turbulence. Vanpée and Wolfhard [9] found correlations between the "ignition temperature" of the jet (below which ignition fails) and the "limit flame temperature" of the successful flame, for several fuels. Wolfhard [10] observed that nitrogen and carbon dioxide have similar minimum jet temperature for ignition, while argon and helium require higher jet

\footnotetext{
${ }^{1}$ Corresponding author.

Contributed by the Combustion and Fuels Committee of ASME for publication in the Journal of Engineering for Gas Turbines and Power. Manuscript received August 26, 2013; final manuscript received October 4, 2013; published online December 12, 2013. Editor: David Wisler.
}

temperature. Fink and Vanpée [11] developed an overall rate expression for ignition of methane- and ethane-air mixtures by low-velocity hot inert gas jets. Cato and Kuchta [12] experimented with laminar hot air jets and identified jet base temperature, jet dimensions, composition of the combustible mixture, and jet velocity, as ignition determining factors.

Toulson et al. [1] reviewed turbulent jet ignition systems for prechamber spark-ignition engines. The prechamber mixture is well controlled and reliably spark ignited, producing a reactive hot jet that acts as a distributed ignition source for the main CVC charge. This allows reliable combustion over a broader range of air-fuel ratios, shorter flame travel distances, and more rapid combustion in otherwise slow-burning lean mixtures. Chemically reactive radicals (e.g., $\mathrm{H}$ and $\mathrm{OH}$ ) and jet-induced turbulence are estimated as equivalent to two orders of magnitude higher energy than spark ignition [2]. Tarzhanov et al. [13] investigated using hot detonation products to detonate stagnant propane-air mixtures and found that detonation initiation depends on the initial volume concentrations, mass fraction of hot detonation products, and the energy deposited from the detonation products. Mayinger et al. [14] derived correlations between the induction time (ignition delay time), the mixing time of the jet, and the adiabatic autoignition time for the fuel-air mixtures.

Bilgin [15] developed a constant-volume combustor (CVC) with long aspect ratio and square cross section, representing a wave rotor channel. The CVC was ignited by a jet of hot combustion products from a separately fueled prechamber that could be spun to cause the jet to traverse one end of the CVC [16]. The relative motion reproduces the action of a wave rotor channel, and the prechamber may be representative of a previously combusted channel supplying hot gas. Bilgin proposed a correlation between the Damköhler number and ignition of a fuel-air mixture in the CVC. For the geometry of this CVC, Baronia et al. [17] performed numerical simulations for a centered stationary (nontraversing) torch jet case using global reaction mechanisms (one-step and four-step) for a propane-air mixture. Bilgin's measurements were not well matched by Baronia's simulations, possibly due to lack of detailed chemical kinetics and a turbulence-chemistry interaction model. Perera [5] carried out experiments on the same CVC test rig for three fuels - methane, ethylene, and propane-varying the equivalence ratios in the prechamber and the CVC chamber. The prechamber was set stationary and centered on the CVC cross section in these tests. The ignition delay time and the ignitability 
limits, both lean and rich, were investigated for all three fuels in the CVC chamber, with fixed atmospheric initial conditions. The variation of ignition delay time for fuels with different prechamber equivalence ratios and nozzle geometry were also observed. More recently, propane and ethylene fuels were ignited in a similar $\mathrm{CVC}$ chamber with rotating motion of the prechamber relative for varying jet traverse speeds [18].

Ignition by inert or reactive hot jets has been sometimes modeled using global reaction mechanisms [17], and no studies are known that employ detailed or skeletal reaction mechanisms. The present work seeks to use detailed numerical simulations to investigate the ignition by a traversing hot jet of combustion products injected into a constant-volume main chamber with long aspect ratio similar to a wave rotor channel. The study is carried out for stoichiometric mixtures of ethylene and methane in this $\mathrm{CVC}$ main chamber at atmospheric conditions. The traversing jet is attached to a rotating prechamber that generates gaseous combustion products. The hot jet is composed of products of rich ethylene combustion in the prechamber.

\section{Problem Description and Numerical Method}

The constant-volume combustor (Fig. 1) used for ignition experiments has a main CVC chamber with square cross section of side $39.9 \mathrm{~mm}$ (1.57 in.) and is $406 \mathrm{~mm}$ (16.0 in.) long. The prechamber internal cavity is of cylindrical design, $166 \mathrm{~mm}$ (6.52 in.) in diameter and width $39.1 \mathrm{~mm}$ (1.54 in.), forming an internal volume of approximately $8.4 \times 10^{-4} \mathrm{~m}^{3}$ (51 cubic inches). The exit diameter of the converging nozzle that connects the prechamber with the CVC chamber is $5.99 \mathrm{~mm}(0.236 \mathrm{in}$.). The small gap between the prechamber and CVC chamber is not modeled, as it is assumed that the gas outflow is negligible at low pressure before ignition occurs in the CVC chamber.

A two-dimensional (2D) model (Fig. 2) of the combustor and jet is used to simulate the transient, turbulent, reacting, and compressible flow at reasonable computational cost. For the 2D simulation, the height and length of the channel and nozzle are the same as those in the test rig. The vertical width of the nozzle is taken to be equal to the corresponding diameter. While this does not preserve the area ratio, it does retain the relative height ratio of the confined jet. However, the volume ratio of the prechamber to the test channel is preserved, neglecting the small volume of the nozzle. This allows the same nondimensional volume flow rate between the experiment and 2D numerical calculations, preserving mass and energy realism and the nominal pressure history. The simulation uses the velocity-pressure coupled, second-order implicit scheme available in the computational code used for this work [19]. The computational domain is discretized using polyhedral meshes with varying mesh density in the prechamber, converging nozzle, and CVC chamber.

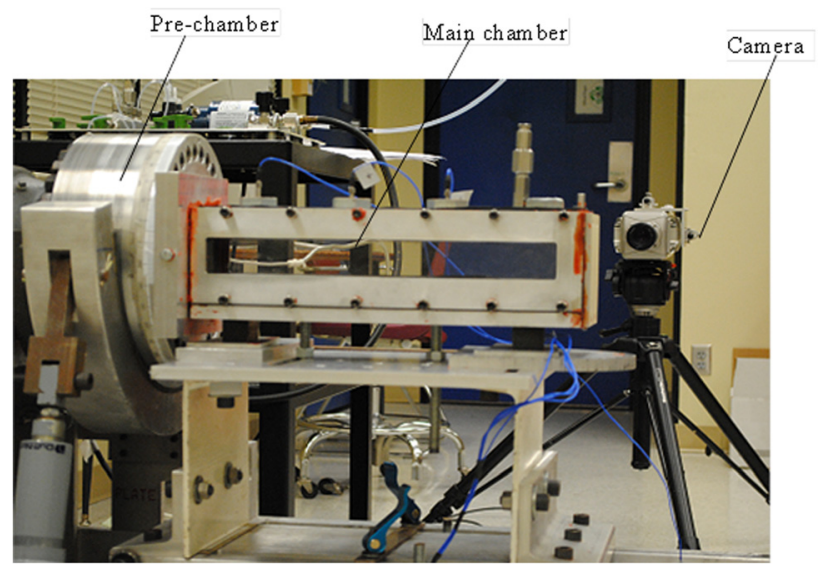

Fig. 1 Constant-volume combustor rig

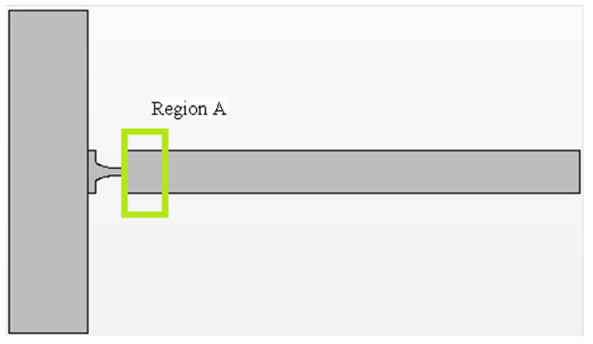

(a)

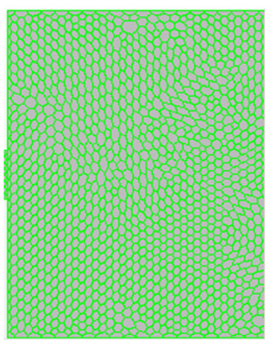

(b)

Fig. 2 Geometry used for simulation (a) geometry used for the analysis $(b)$ enlarged view of polyhedral mesh

Turbulence is modeled using the shear-stress-transport (SST) two-equation k- $\omega$ model [20]. Combustion is modeled using a hybrid eddy-breakup model that considers finite-rate chemistry. The classic eddy-breakup (EBU) turbulent reaction model was presented by Spalding [21] and later developed by Magnussen and Hjertager [22]. The present work uses a hybrid EBU model, with each reaction rate modeled as the minimum of the EBU rate and the kinetic reaction rate from detailed chemistry reported below. A good review of turbulent combustion models, including hybrid EBU models, is made by Hilbert et al. [23]. There are several studies that fruitfully employ hybrid EBU models $[23,24]$.

The reaction mechanism used for ethylene involves 32 species in 206 reversible elementary reactions [25] and is derived from USC Mech-II [26]. For methane, a detailed reaction mechanism DRM19 [27] is used, which involves 21 species in 84 reversible reactions and is derived from GRI Mech 1.2 [28].

The initial pressure in the prechamber is specified as the pressure at diaphragm rupture measured from experiments [7]. The initial temperature and composition of the prechamber is obtained by chemical equilibrium calculation of major product species for combustion of ethylene-air with the equivalence ratio of 1.1 . The calculation used the program developed by Depcik [29], which correlates well with the NASA equilibrium code [30]. The initial conditions for the prechamber and CVC chamber are listed in Table 1 and are the same for all the simulations in the present work.

A grid-sensitivity study was previously completed considering propane-air mixture in the CVC chamber and inert hot jet (argon), using a one-step reaction mechanism for simplicity. Three different grid sizes were used for the CVC chamber with minimum cell sizes of $1.2 \mathrm{~mm}(15,597$ total cells), $1.0 \mathrm{~mm}(20,834$ total cells), and $0.5 \mathrm{~mm}(63,728$ total cells). The solutions for the two finer grids were found to differ very little [31], and therefore, the grid with minimum cell size $1.0 \mathrm{~mm}$ in the CVC chamber is used for the detailed simulations. It should be noted that the present study is not intended to resolve the flame thickness after ignition nor estimating flame speed after ignition. The mesh used here is intended to predict the ignition delay time but may not be adequate for predicting subsequent flame propagation. 
Table 1 Initial conditions considered for the simulations

\begin{tabular}{lccc}
\hline \hline \multirow{2}{*}{$\begin{array}{l}\text { Thermodynamic } \\
\text { properties and } \\
\text { mass fractions }\end{array}$} & Prechamber & Methane & Ethylene \\
\cline { 3 - 4 } & 649.0 & 101.325 & 101.325 \\
Pressure $(\mathrm{kPa})$ & 2770 & 298 & 298 \\
Temperature $(\mathrm{K})$ & 0.0069176 & 0.219231 & 0.217271 \\
$\mathrm{O}_{2}$ & 0.719410 & 0.725824 & 0.719240 \\
$\mathrm{~N}_{2}$ & 0.142050 & 0 & 0 \\
$\mathrm{CO}_{2}$ & 0.050400 & 0 & 0 \\
$\mathrm{CO}$ & 0.000739 & 0 & 0 \\
$\mathrm{H}_{2}$ & 0.080490 & 0 & 0 \\
$\mathrm{H}_{2} \mathrm{O}$ & 0 & 0.054945 & 0 \\
$\mathrm{CH}_{4}$ & 0 & 0 & 0.063488 \\
$\mathrm{C}_{2} \mathrm{H}_{4}$ & 0 &
\end{tabular}

\section{Ignition Delay and Combustion Characteristics}

Ignition Delay and Jet Speed. There are many definitions of ignition delay time used in the literature, most of which refer to autoignition by rapid or shock compression of a fuel-oxidant mixture with no trace of other highly reactive species initially present. Hot-jet ignition and autoignition have common and different challenges in defining the ignition delay time. Ignition could reasonably be defined as occurring either at the time of maximum rate of change or at the time when the peak value of some species or variable such as $[\mathrm{OH}],[\mathrm{CH}]$, or pressure is reached or could be based on an extrapolation of the maximum slope to the zero signal level. Davidson and Hanson [8] reported that, in general, pressure rise is a good indicator of ignition at high fuel concentrations. They also found that the $\mathrm{CH}^{*}$ (formed by the reaction, $\mathrm{C}_{2} \mathrm{H}+\mathrm{O} \rightarrow$ $\mathrm{CH}^{*}+\mathrm{CO}$, where $\mathrm{CH}^{*}$ represents the excited state) and $\mathrm{OH}$ (and intermediate species $\mathrm{C}_{3} \mathrm{H}_{6}$ ) mole fraction histories show clear evidence of a change owing to ignition for the cases investigated. Hot-jet ignition also involves a physical delay for mixing with the cold combustible gas. The active radical species introduced may influence reaction initiation of the fresh fuel but may also be quenched during entrainment of cold mixture, depending on the entrainment ratio and mixing rate. Examination of fuel consumption rate or production rates of some of the intermediate species may not adequately define ignition delay.

High-speed video images taken through a transparent window of the experimental CVC with traversing hot-jet ignition are presented in Fig. 3, for a methane mixture in the CVC chamber, with optically obscured volume indicated in green. The camera spectral response is $400-1000 \mathrm{~nm}$, capturing visible and near-infrared luminosity of hydrocarbon combustion, which comes from soot radiation. In Fig. 3(a), ignition of a stoichiometric methane-air mixture by a centered stationary jet is observed. In Fig. 3(b), igni-

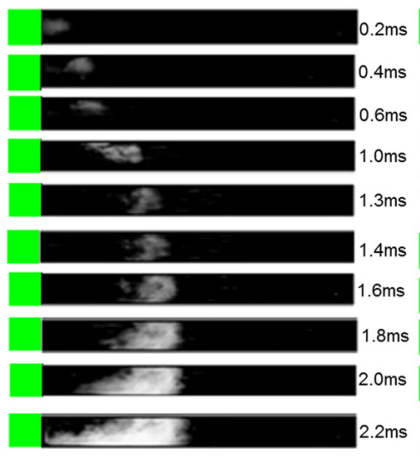

(a)

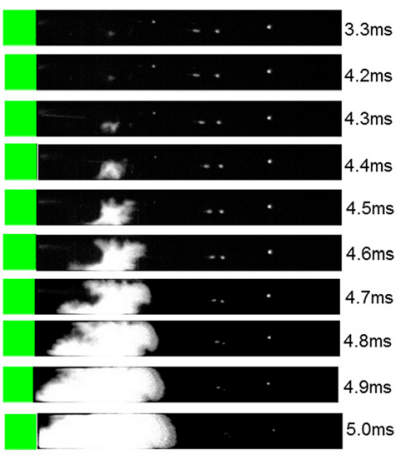

(b)
Fig. 3 High-speed video images of ignition of (a) $\Phi=1$ methane mixture in the main CVC chamber, for centered stationary jet [7]; $(b) \Phi=0.8$ methane mixture in the main CVC chamber for near-wall jet
Table 2 Jet traverse speed and traverse time

\begin{tabular}{lcc}
\hline \hline Spin rate $(\mathrm{rpm})$ & Traverse speed $(\mathrm{m} / \mathrm{s})$ & Traverse time $(\mathrm{ms})$ \\
\hline 150 & 0.983 & 40.5 \\
750 & 4.917 & 8.1 \\
2000 & 13.112 & 3.1 \\
\hline \hline
\end{tabular}

tion of a lean methane-air mixture is observed, with prechamber spin rate of $150 \mathrm{rpm}$, which corresponds to a jet traverse speed of $0.983 \mathrm{~m} / \mathrm{s}$ and a traverse time of $40.5 \mathrm{~ms}$. At this speed, the jet barely moves away from the side wall before ignition is completed. Thus, the jet structure, penetration, and entrainment for the near-wall position, rather than the traversing motion, are likely to be its distinguishing characteristic. Therefore, this slowly traversing case will be referred to as the 'near-wall' jet. It can be seen that the jet initially travels along the wall and later impinges on the bottom wall. Rapid onset of combustion can be seen to start at around $1.4 \mathrm{~ms}$ after the impingement of the jet and progresses towards both ends of the CVC chamber.

Experimental data have not been published for faster traversing jets; this work is intended to anticipate that data with numerical simulations. More advanced optical diagnostic tools often seek to measure excited species such as $\mathrm{OH}$, but it is not obvious what measurements would provide a reliable indication of ignition and ignition delay time. The prechamber spin rates and the corresponding jet traverse speeds and the traverse times for the numerical simulations reported are listed in Table 2.

It is expected that numerical simulations will capture the jet behavior and ignition trends similar to the experiments and provide a deeper understanding of the interplay between physical and chemical processes. However, it is not expected that the jet impingement time and ignition delay time from simulations would match quantitatively with experimental data due to lack of realism of the two-dimensional approximation in the simulations. The forthcoming discussion is based entirely on computer simulations, motivated and anchored by the currently limited experimental data, and to provide guidance for future experiments.

In Fig. 4, the mass fraction levels of the combustion of stoichiometric ethylene/air and methane/air mixtures in the CVC chamber are presented for the near-wall jet. The traversing jet is seen to impinge on the CVC chamber bottom wall at $0.4 \mathrm{~ms}$ forming counterrotating vortices that entrain the CVC mixture. It is also observed that the "flame surface" boundary between unburned ethylene air mixture and the entrained and consumed region retreat toward the injection end of the channel at about $1.2 \mathrm{~ms}$, and immediately afterwards the flame surface becomes more highly convoluted. This is due to a shock wave that is generated by the jet initiation and initial heat release and travels away from the flame. Upon reflection at the opposite end, the shock wave

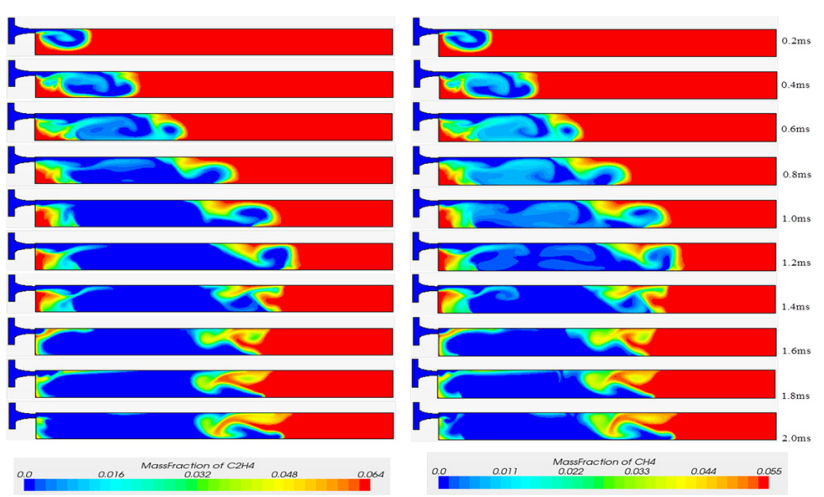

Fig. 4 History of fuel mass fraction for ethylene (left) and methane (right) in stoichiometric mixtures for near-wall jet 


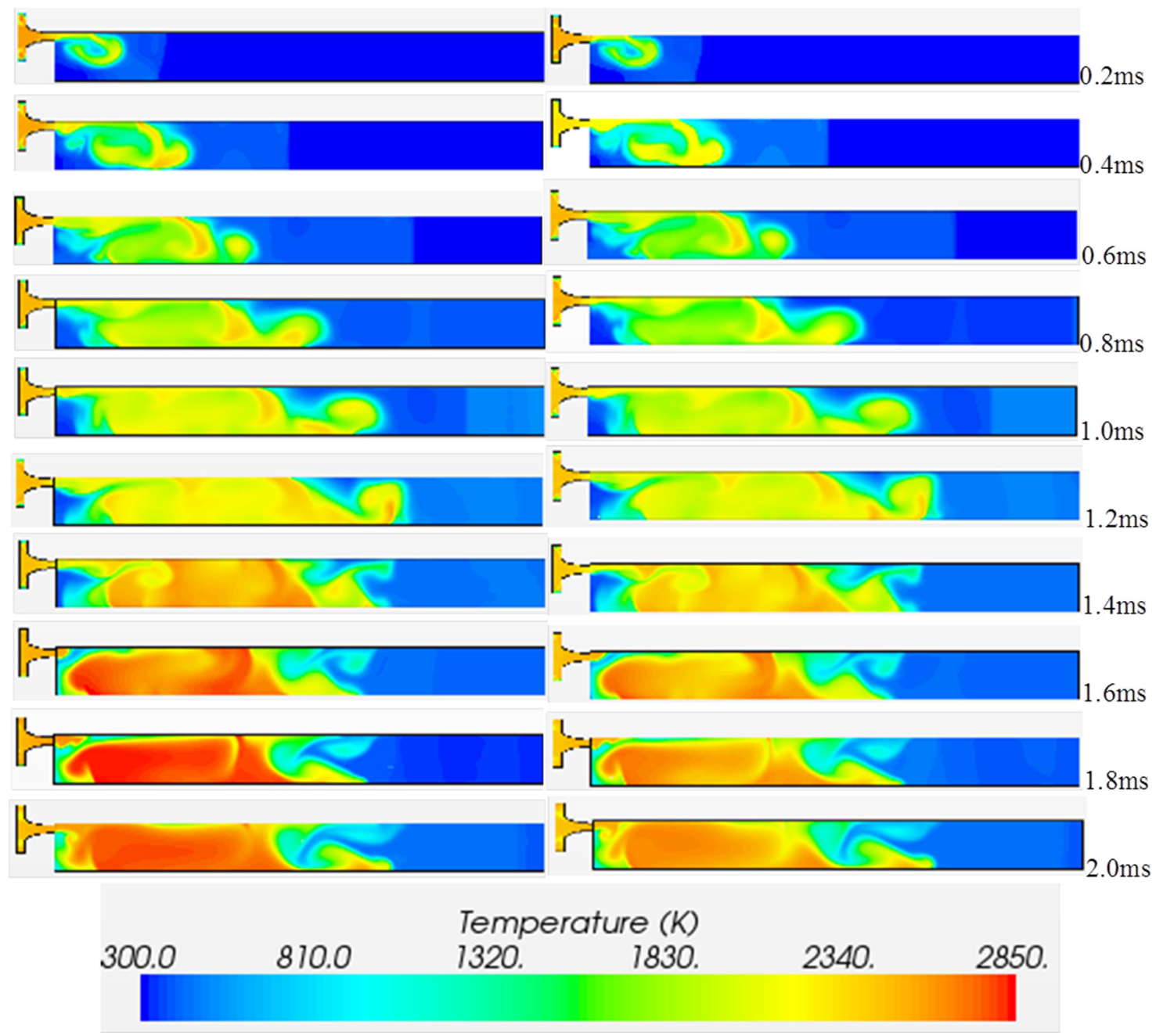

Fig. 5 History of temperature levels for ethylene (left) and methane (right in stoichiometric mixtures for nearwall jet

returns to reverse the general direction of gas motion (giving the appearance of flame retreating) and, more importantly, deposits significant baroclinic vorticity on the nonplanar flame surface, significantly increasing in flame area. The shock wave also increases gas temperatures in the combusting region, thus accelerating kinetic rates. Thus, in all cases, a significant increase in fuel consumption is observed at this time. Although the overall vortex dynamics and entrainment flows are very similar, it can be seen within the mixed regions that ethylene reacts significantly faster than methane. As methane is less reactive than ethylene, its greater sensitivity to jet mixing patterns and rates may be understood with deeper examination of the chemical kinetics of reaction. In the temperature level plots presented in Fig. 5 for the near-wall jet, higher temperature rise in the CVC chamber can be observed for the ethylene/air mixture compared to the methane/air mixture. The constant-volume combustion adiabatic flame temperature for methane and ethylene are found to be $2821 \mathrm{~K}$ and $3116 \mathrm{~K}$, respectively, for atmospheric initial conditions assuming single step reaction.

To analyze the effect of traversing jet speed, the averaged fuel consumption history in the CVC chamber for the ethylene mixture at different jet traversing speeds is compared with the centered stationary case in Fig. 6. The trends in ethylene fuel consumption are similar for the traversing jet at different speeds and for the centered stationary jet, with rapid combustion rates after about $1.2 \mathrm{~ms}$ after start of injection but with some differences. Because of the low autoignition temperature of ethylene, higher combustion temperature, and fast reaction rates, the Damkohler number
(Da, ratio of reaction rate to mixing rate of vortices) is large, and ignition occurs early and relatively independent of variations in jet and entrainment behavior. For all traverse cases, the arrival of the reflected shock at about $1.2 \mathrm{~ms}$ does accelerate the reaction rate moderately.

The fuel consumption histories in the CVC chamber for methane mixture predicted from simulations are presented in Fig. 7 for the centered stationary jet and different traversing jet speeds. In the case of methane mixture in the CVC chamber, the reaction is initially relatively slow, more so for the centered stationary jet. It is seen that the fuel consumption rate sharply increased between $1.2 \mathrm{~ms}$ to $1.5 \mathrm{~ms}$, consistent with the returning shock compression and flame distortion during this period but with significantly more effect for the centered stationary jet than the near-wall slowly traversing jet. For the near-wall jet, the peak fuel consumption rate is relatively lowest. The relatively slow kinetics and high autoignition temperature of methane result in a greater role for jet and entrainment behavior in determining the local Damkohler number and the ignition delay time. These faster-traversing hot jets move through positions from near-wall toward and past the centerline position, thus having more complex vortex generation and entrainment dynamics.

For a better understanding of methane combustion progress and heat release with varying jet behavior, the CVC temperature levels are plotted in Fig. 8. One noticeable difference is that the temperature rise is lower in case of centered stationary jet when compared to all the traversing jet cases. For example, at $2.0 \mathrm{~ms}$, temperature is higher for the jets traversing at the three speeds compared to the 


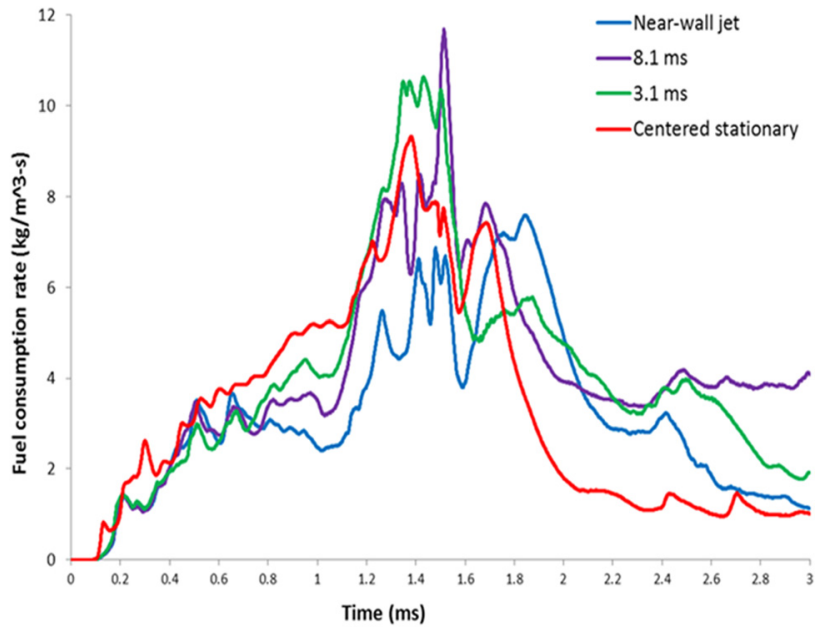

Fig. 6 CVC chamber-averaged fuel consumption rate for traversing jets and centered stationary jet for stoichiometric ethylene-air mixture

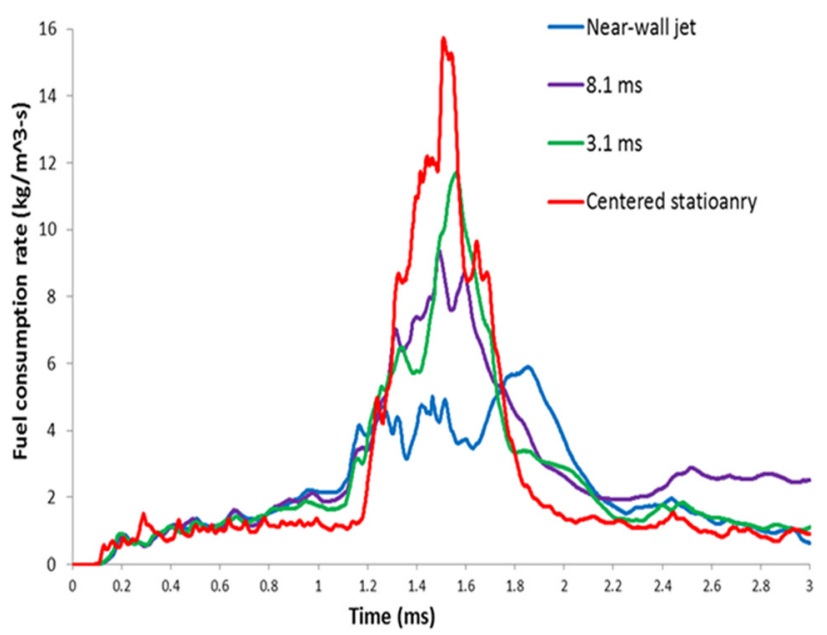

Fig. 7 CVC chamber-average fuel consumption rate for traversing jests and centered stationary jet for stoichiometric methane-air mixture

centered stationary jet. Moreover, earlier temperature rise is seen in the case of the near-wall jet speed case compared to other cases. It appears that the initial jet position and traverse speeds can significantly affect the time of the combustion and its progress. Closer observation of the gas distribution and temperature field at about $1.0 \mathrm{~ms}$, before the shock-flame interaction, shows that the centered jet has significantly more penetration and, thus, entrains more fuel-air mixture but has lower overall temperature, probably due to the lower concentrations of injected hot gas as a result. Consumption of fuel is also lower at $1.0 \mathrm{~ms}$ for this jet (Fig. 7). Thus, for the centered jet, more fuel is mixed with hot gas creating a leaner mixture with more unreacted fuel, which is then rapidly consumed when the shock interacts. It is further seen that the heat release and temperature rise occur later for the centered jet, and the overall consumption rate plummets when the mixed region expands by about $2.0 \mathrm{~ms}$.

To analyze the combustion progress and reaction pathways, the production and consumption behavior of several significant intermediate species is presented below.

Reaction Pathways and Combustion Progress. The significantly different consumption rate of fuel in the CVC chamber for methane mixture for the near-wall and centered stationary jets
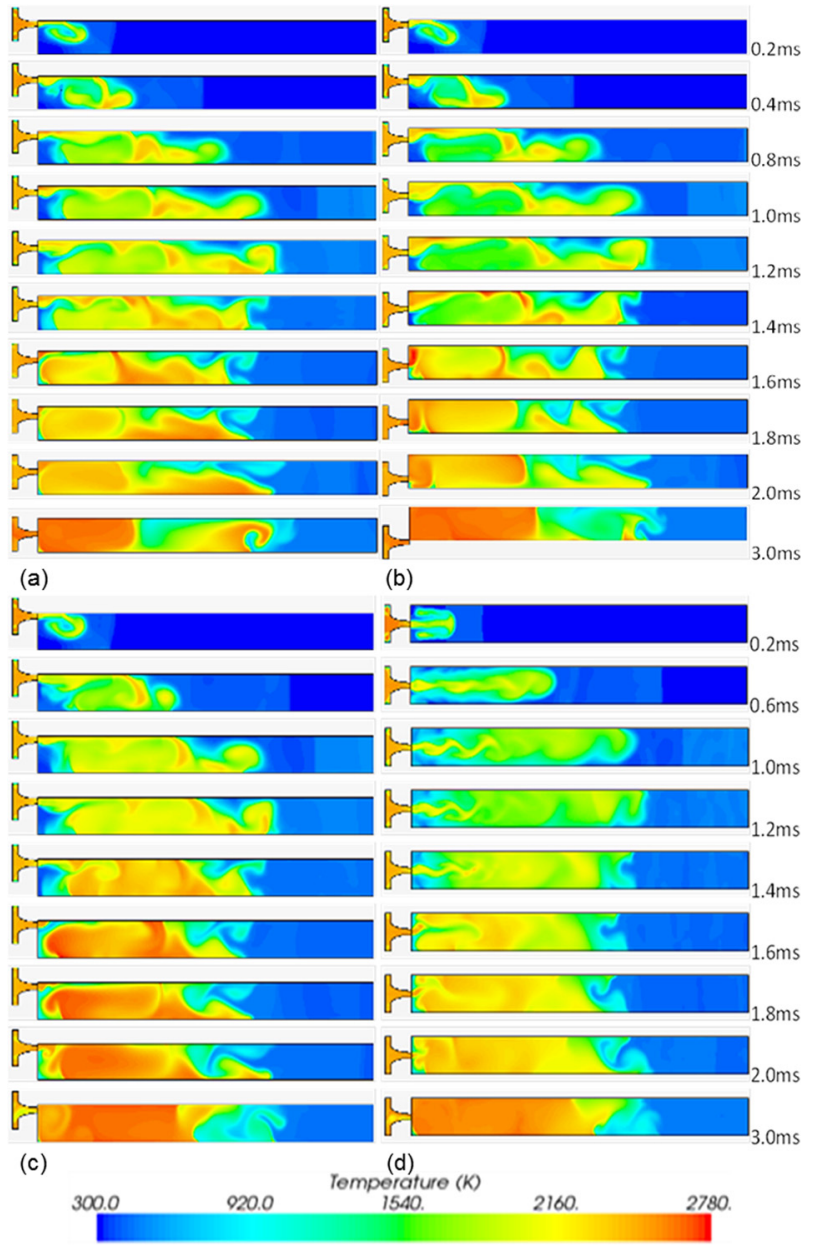

Fig. 8 Temperature levels for methane mixture for (a) $8.1 \mathrm{~ms}$ traverse, (b) $3.1 \mathrm{~ms}$ traverse, (c) near wall, and (d) centered stationary

could be explained by looking at the prominent intermediate species. An important $\mathrm{C} 2$ intermediate species in the combustion of methane is ethylene, $\mathrm{C}_{2} \mathrm{H}_{4}$, which was earlier studied as a fuel itself. Figure 9 is a comparison of the mass fraction of ethylene for the centered stationary case and different traversing jet cases of methane combustion. It can be seen that there is very high production of ethylene from $1.4 \mathrm{~ms}$ to $1.8 \mathrm{~ms}$ for the centered stationary case with the highest mass fraction at $1.6 \mathrm{~ms}$. Interestingly, such high ethylene production is not seen for the near-wall jet case. This sudden production of ethylene is also less prominent for the faster traversing jet cases when compared to the centered jet case. This may be explained by the enhanced mixing with lower entrainment for the near-wall jet due to jet impingement producing counterrotating vortices. To gain further insight, the mass fraction of intermediate species $\mathrm{OH}$ is compared in Fig. 10. It shows that the high production of $\mathrm{OH}$ starts as early as $1.6 \mathrm{~ms}$ for near-wall jet case while for the centered jet case the same level of $\mathrm{OH}$ production is seen much later at around $2.4 \mathrm{~ms}$. It can also be observed that the production of $\mathrm{OH}$ is seen to occur in the enhanced mixing zone where the counterrotating vortices evolve after the jet impinges on the wall. It can be concluded that for the near-wall jet case the enhanced mixing in a smaller volume causes the faster completion of reaction.

Further insight may be obtained by examining the globally averaged histories of two important $\mathrm{C} 1$ and $\mathrm{C} 2$ hydrocarbon intermediate species, $\mathrm{CH}_{3}$ and $\mathrm{C}_{2} \mathrm{H}_{4}$, shown in Fig. 11. These species are relatively unstable and exist more in newly reacting regions such as the propagating flame front and slower mixing regions. It 


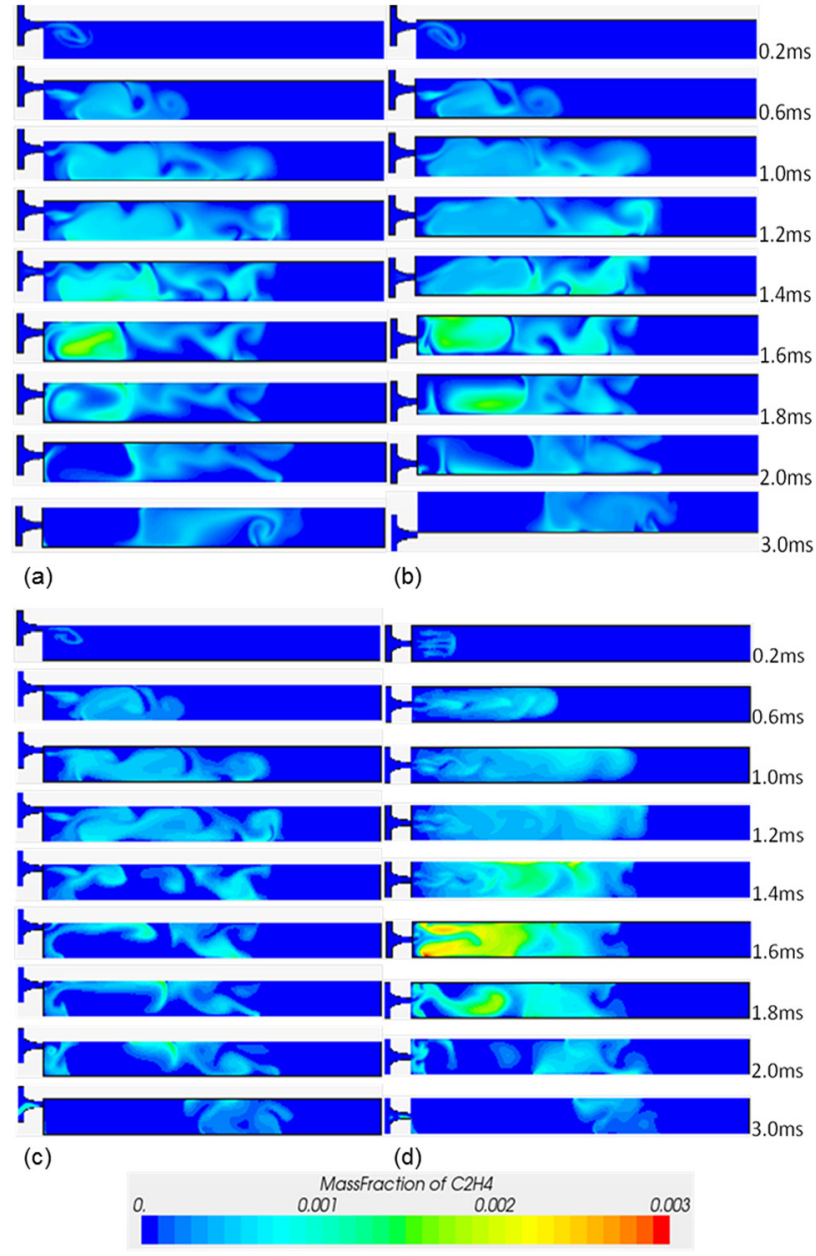

Fig. $9 \quad \mathrm{C}_{2} \mathrm{H}_{4}$ mass fraction contours for methane mixture at (a) $8.1 \mathrm{~ms}$ traverse jet, (b) $3.1 \mathrm{~ms}$ traverse jet, (c) near-wall jet, and (d) centered stationary jet

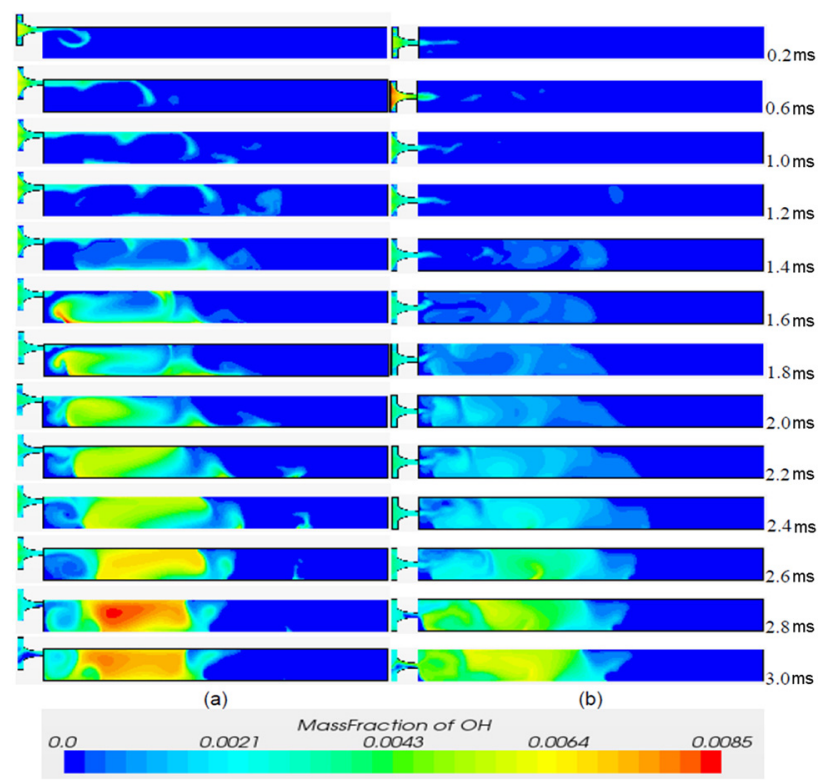

Fig. $10 \mathrm{OH}$ mass fraction contours for methane mixture in (a) near-wall jet and $(b)$ centered stationary jet

can be seen for the centered stationary jet that $\mathrm{CH}_{3}$ and $\mathrm{C}_{2} \mathrm{H}_{4}$ are present in significant amounts and then consumed. On the other hand, for the near-wall and traversing jets, the presence of $\mathrm{CH}_{3}$

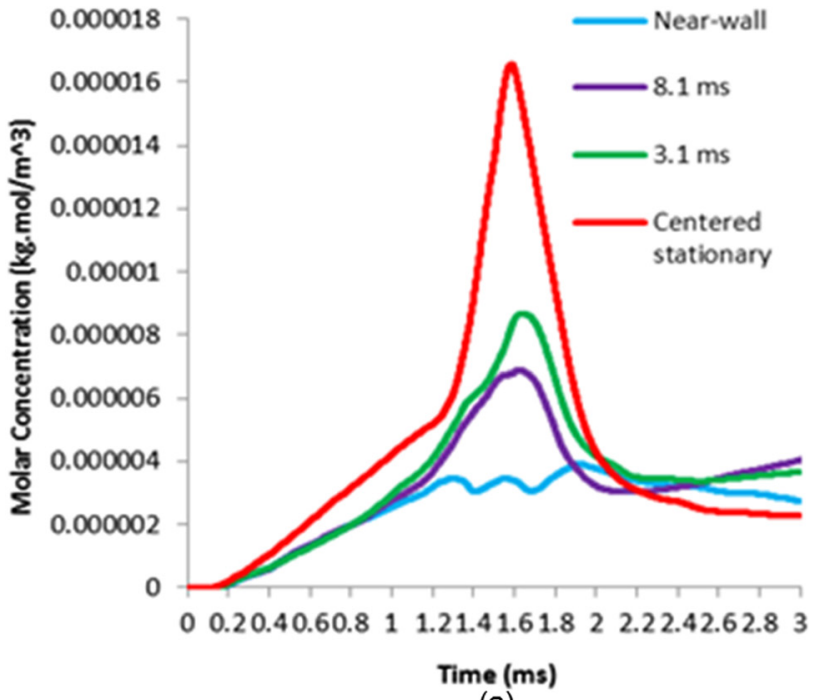

(a)

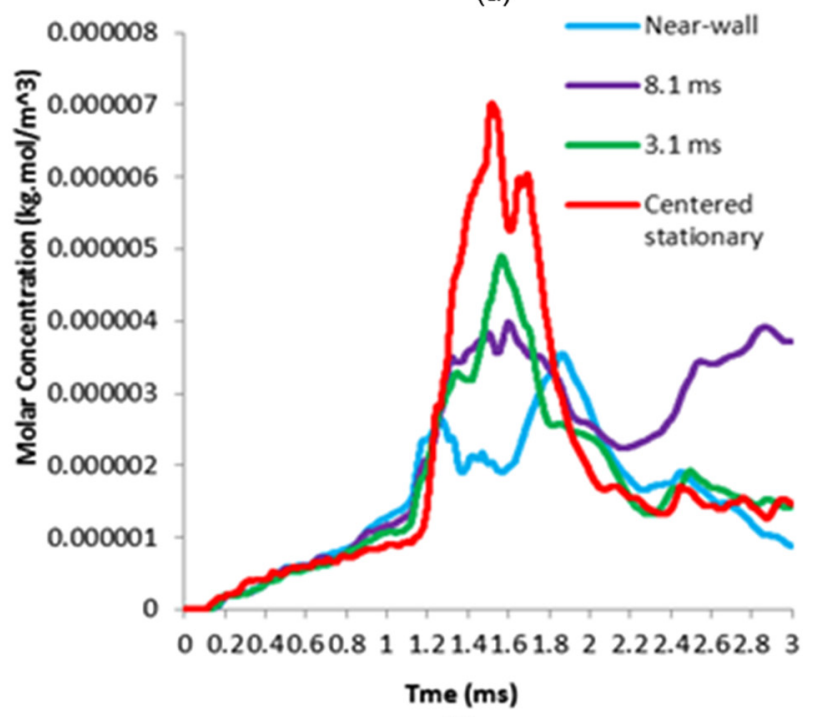

(b)

Fig. 11 CVC chamber-averaged molar concentration histories of (a) $\mathrm{CH}_{3}$ and (b) $\mathrm{C}_{2} \mathrm{H}_{4}$ intermediate species in the CVC chamber for stoichiometric methane mixture

and $\mathrm{C}_{2} \mathrm{H}_{4}$ is lower, indicating that production is more closely followed by consumption. In contrast to $\mathrm{C} 1$ and $\mathrm{C} 2$ species, $\mathrm{OH}$ and $\mathrm{H}$ are key radical species that are generated during continuing chain-propagation reactions of the combustion process. The presence of $\mathrm{OH}$ and $\mathrm{H}$ is seen (Fig. 12) to increase dramatically between $1.6 \mathrm{~ms}$ to $2.6 \mathrm{~ms}$ for all the cases but with higher levels for the near-wall jet compared to the centered stationary and faster traverse cases. This supports the hypothesis that a jet with reduced entrainment and enhanced mixing can lead to faster progress of combustion. Based on $\mathrm{OH}$ and $\mathrm{H}$, the ignition delay would appear to about $2 \mathrm{~ms}$, but based on fuel consumption, an earlier time is indicated. This highlights the importance of not relying on a single or indirect measure of ignition activity.

Future work on this topic may include detailed combustion modeling of the prechamber to accurately determine the hot jet composition, which is assumed here to include only major species, but in reality may include traces of highly reactive radicals that can influence ignition. A numerical model of heat losses will also be helpful to estimate the jet temperature more accurately, as it is difficult to verify gas temperature experimentally. Validation against experiments requires a fully three-dimensional transient computation, which can be more affordable with advanced methods such as adaptive mesh refinement and efficient kinetic rate 


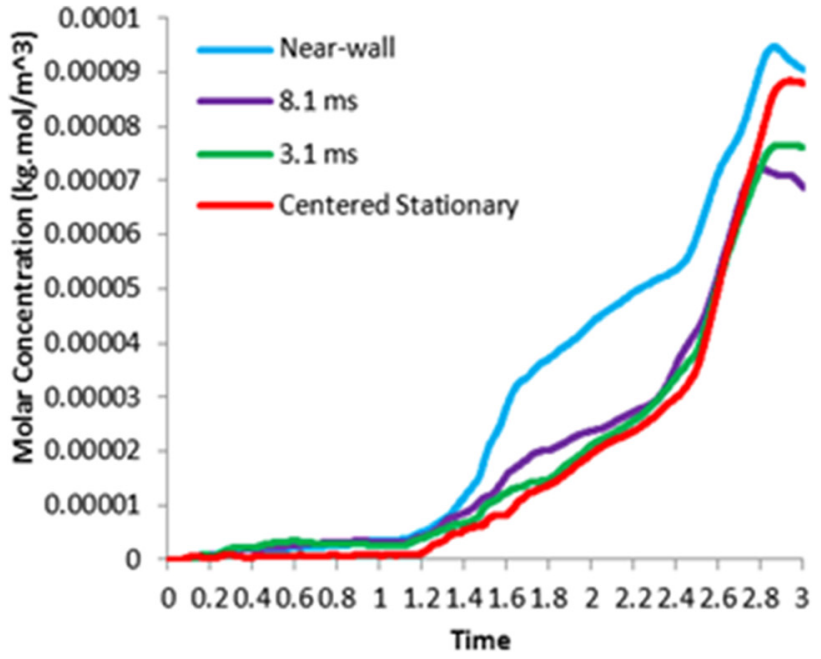

(a)

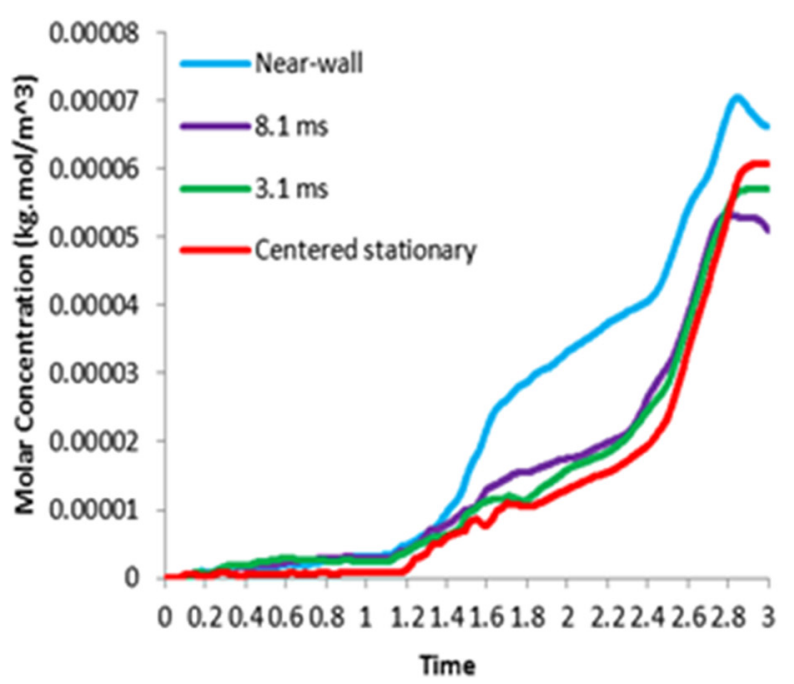

(b)

Fig. 12 CVC chamber-averaged molar concentration histories of $\mathrm{OH}$ and $\mathrm{H}$ intermediate species in the CVC chamber for stoichiometric methane mixture

computation. Further, the hybrid EBU model used in the present study could be compared with other turbulent combustion models, as well as purely kinetic models. This would be useful if species data were available from experiments, for example, $\mathrm{OH}$ radical sensing by laser-induced fluorescence and direct indicators of heat release rate.

\section{Conclusions}

Hot jet ignition of combustible mixture in a constant-volume combustor is investigated numerically. The chemically active hot jet issued from the prechamber ignites the CVC chamber stoichiometric fuel mixture at atmospheric conditions. The confined traversing jet at slow traverse speed is observed to behave initially as a wall jet and later as a wall-impinging jet, whereas the centrally located stationary jet behaves somewhat like a free jet with confined vortices. The ignition delay time and reaction pathways of the combustion of ethylene and methane in air are studied. It is observed that the ignition delay time for methane combustion is more difficult to quantify than the ignition delay time of ethylene, with greater sensitivity to entrainment rate, jet-vortex dynamics, and chamber gas dynamic wave transients. With the central sta- tionary jet, greater penetration results in more entrainment of methane-air mixture. This implies more dilution of the jet, as evidenced by lower peak temperature, high levels of $\mathrm{C} 1 / \mathrm{C} 2$ intermediate species produced and then consumed, and delayed production of $\mathrm{OH}$ and $\mathrm{H}$ species that indicate significant reaction progress. On the other hand, the slow-traverse near-wall jet entrains less mixture and appears to promote faster ignition, based on earlier appearance of $\mathrm{OH}$. Measurement of one or a few active species may not provide a reliable measure of ignition and ignition delay time for all types of jet ignition and all fuels. Criteria that are based on initial disappearance of fuel may indicate different trends than criteria that track completion of combustion.

\section{Acknowledgment}

The work was partially supported by the National Science Foundation, under grant NSF/CBET-1235696. Financial and computational support from the Purdue University School of Engineering and Technology at IUPUI is also acknowledged

\section{References}

[1] Toulson, E., Schock, H. J., and Attard, W. P., 2010, "A Review of Pre-Chamber Initiated Jet Ignition Combustion Systems," SAE Paper No. 2010-01-2263.

[2] Attard, W. P., Toulson, E., Huisjen, A., Chen, X., Zhu, G., and Schock, H., 2012, "Spark Ignition and Pre-Chamber Turbulent Jet Ignition Combustion Visualization," SAE Paper No. 2012-01-0823.

[3] Lieberman, D. H., and Shepherd, J. E., 2002, "Detonation Initiation by Hot Turbulent Jet for Use in Pulse Detonation Engines," 38th Joint Propulsion Conference, Indianapolis, IN, July 7-10, AIAA Paper No. 2002-3909.

[4] Matsutomi, Y., Meyer, S. E., Wijeyakulasuriya, S. D., Izzy, Z., Nalim, M. R. Shimo, M., Kowalkowski, M., and Snyder, P. H., 2010, "Experimental Investigation on the Wave Rotor Combustor," 46th Joint Propulsion Conference, Nashville, TN, July 25-28, AIAA Paper No. 2010-7043.

[5] Perera, U. I., Wijeyakulasuriya, S. D., and Nalim, M. R., 2011, "Hot Combustion Torch Jet Ignition Delay Time for Ethylene-Air Mixtures," 49th Aerospace Sciences Meeting, Orlando, FL, January 4-7, AIAA Paper No. 2011-95.

[6] Akbari, P., and Nalim, M. R., 2009, "Review of Recent Developments in Wave Rotor Combustion Technology,” AIAA J. Propul. Power, 25(4), pp. 833-844.

[7] Perera, U. I., 2010, "Experimental Investigation Into Combustion Torch Jet Ignition of Methane-Air, Ethylene-Air, and Propane-Air Mixtures," M.S. thesis, Purdue University, Indianapolis, IN.

[8] Davidson, D. F., and Hanson, R. K., 2004, "Interpreting Shock Tube Ignition Data," Int. J. Chem. Kinetics, 36(9), pp. 510-523.

[9] Vanpée, M., and Wolfhard, H. G. 1959, "Comparison Between Hot Gas Ignition and Limit Flame Temperatures," Am. Rocket Soc. J., 29(7), pp. 517-519.

[10] Wolfhard, H. G., 1958, "The Ignition of Combustible Mixtures by Hot Gases," Jet Propul., 28(12), pp. 798-804.

[11] Fink, Z. J., and Vanpée, M., 1975, "Overall Kinetics of Hot Gas Ignition," Combust. Sci. Tech., 11(5-6), pp. 229-238.

[12] Cato, R. J., and Kuchta, J. M., 1966, "Hot Gas Ignition Temperatures of Hydrocarbon Fuel Vapor-Air Mixtures," U.S. Department of the Interior, Bureau of Mines, AD0643518.

[13] Tarzhanov, V. I., Telichko, I. V., Vil'danov, V. G., Sdobnov, V. I., Makarov, A. E., Mukhin, S. L., Koretskii, I. G., Ogarkov, V. A., Vlasov, V. V., Zinchenko, A. D., Vorob'ev, A. V., Grachev, A. N., Matkin, V. A., and Potashnikov, V. A., 2006, "Detonation of Propane-Air Mixtures Under Injection of Hot Detonation Products," Combust. Explos. Shock Waves, 42(3), pp. 336-345.

[14] Mayinger, F., Jordan, M., Eder, A., Zaslonko, I. S., Karpov, V. P., and Frolov, S. M., 1999, "Flame-Jet Ignition of Fuel-Air Mixtures. Experimental Findings and Modeling," 17th International Colloquium on the Dynamics of Explosions and Reactive Systems (ICDERS), Heidelberg, Germany, July 25-30.

[15] Bilgin, M., 1998, "Stationary and Rotating Hot Jet Ignition and Flame Propagation in a Premixed Cell," Ph.D. dissertation, Aeronautics and Astronautics Dept., University of Washington, Seattle, WA.

[16] Bilgin, M., Keller, J. J., and Breidenthal, R. E., 1998, "Ignition and Flame Propagation With Rotating Hot Jets in a Simulated Wave Engine Test Cell," AIAA Paper No. 98-3399.

[17] Baronia, D., Nalim, M. R., and Akbari, P., 2007, "Numerical Study of Wave Rotor Ignition and Flame Propagation in a Single-Channel Rig," AIAA Paper No. 2007-5054.

[18] Murphy, K., "Experimental Investigation of Traversing Hot-Jet Ignition of Ethylene, and Propane-Air Mixtures in a Constant-Volume Combustor," M.S.M.E. thesis, Department of Mechanical Engineering, Purdue University, Indianapolis, IN (unpublished in preparation).

[19] User Guide, 2010, "STAR-CCM+ Version 5.06.010," CD-adapco, Melville, NY.

[20] Menter, F. R., 1994, "Two-Equation Eddy-Viscosity Turbulence Modeling for Engineering Applications," AIAA J., 32(8), pp. 1598-1605.

[21] Spalding, D. B., 1971, "Mixing and Chemical Reaction in Steady Confined Turbulent Flames," Symp. (Int.) Combust., 13(1), pp. 649-657. 
[22] Magnussen, B. F., and Hjertager, B. H., 1976, "On Mathematical Modeling of Turbulent Combustion With Special Emphasis on Soot Formation and Combustion," Symp. (Int.) Combust., 16(1), pp. 719-729.

[23] Hilbert, R., Tap, F., El-Rabii, H., and Thévenin, D., 2004, "Impact of Detailed Chemistry and Transport Models on Turbulent Combustion Simulations," Prog. Energ. Combust. Sci., 40, pp. 61-117.

[24] Magel, H. C., Schnell, U., and Hein, K. R. G., 1996, "Simulation of Detailed Chemistry in a Turbulent Combustor Flow," Symp. (Int.) Combust., 26(1), pp. $67-74$.

[25] Luo, Z., Yoo, C. S., Richardson, E. S., Chen, J. H., Law, C. K., and Lu, T. F., 2012, "Chemical Explosive Mode Analysis for a Turbulent Lifted Ethylene Jet Flame in Highly-Heated Coflow," Combust. Flame, 159(1), pp. 265-274.

[26] Wang, H., You, X., Joshi, A. V., Davis, S. G., Laskin, A., Egolfopoulos, F., and Law, C. K., 2007, "USC Mech Version II. High-Temperature Combustion Reaction Model of $\mathrm{H} 2 / \mathrm{CO} / \mathrm{C} 1-\mathrm{C} 4$ Compounds," http://ignis.usc.edu/ USC Mech II.htm
[27] Kazakov, A., and Frenklach, M., "Reduced Reaction Sets Based on GRI-Mech 1.2," University of California at Berkeley, Berkeley, CA, http://www.me.berkeley.edu/drm/

[28] Smith, G. P., Golden, D. M., Frenklach, M., Moriarty, N. W., Eiteneer, B., Goldenberg, M., Bowman, C. T., Hanson, R. K., Song, S., Gardiner, W. C., Lissianski, V. V., and Qin, Z., "GRI-Mech," Gas Research Institute, http://www.me.berkeley.edu/gri_mech/

[29] Depcik, C., 2000, "Open-Ended Thermodynamic Cycle Simulation," M.S. thesis, University of Michigan, Ann Arbor, MI

[30] Gordon, S., and McBride, B. J. 1996, "Computer Program for Calculation of Complex Chemical Equilibrium Compositions and Applications," NASA Reference Publication 1311.

[31] Rajagopal, M., Karimi, A., and Nalim, R., 2012, "Wave Rotor Pressure Gain Combustion Analysis for Power Generation and Gas Turbine Applications," ASME Gas Turbine India Conference, Mumbai, India, December 1, ASME Paper No. GTIndia2012-9741. 